\title{
BMJ Open Visceral leishmaniasis-associated mortality in Bangladesh: a retrospective cross-sectional study
}

\author{
M Mamun Huda, ${ }^{1}$ Rajib Chowdhury, ${ }^{2}$ Debashis Ghosh, ${ }^{1}$ Aditya Prasad Dash, ${ }^{3}$ \\ Sujit Kumar Bhattacharya, ${ }^{4}$ Dinesh Mondal ${ }^{5}$
}

To cite: Huda MM, Chowdhury R, Ghosh D, et al. Visceral leishmaniasisassociated mortality in Bangladesh: a retrospective cross-sectional study. BMJ Open 2014;4:e005408. doi:10.1136/bmjopen-2014005408

- Prepublication history for this paper is available online. To view these files please visit the journal online (http://dx.doi.org/10.1136/ bmjopen-2014-005408).

Received 5 April 2014 Revised 9 June 2014 Accepted 24 June 2014

\section{CrossMark}

For numbered affiliations see end of article.

Correspondence to M Mamun Huda; mhuda83@icddrb.org

\section{ABSTRACT}

Objective: To investigate visceral leishmaniasis (VL) deaths and risk factors in two VL endemic areas of Bangladesh.

Design: Retrospective cross-sectional.

Setting: Two geographically and culturally different VL endemic subdistricts, Godagari in the district of Rajshahi and Trishal in the district of Mymensingh in Bangladesh, August 2009-December 2011.

Participants: 51094 inhabitants from randomly selected Unions in the two subdistricts.

Main outcome measures: VL deaths, confirmed independently by qualified physicians using the verbal autopsy procedure ICD10 guideline.

Results: The total number of people screened for VL deaths was 51094 from 12032 households from Godagari and Trishal subdistricts . About $16 \%$ of the people from Godagari were Tribals. The average age of the study population was 25.6 years (SD 18.4) and $49.7 \%$ were females. The $\mathrm{VL}$ case fatality rate averaged $6.12 \%$ (12/196) including 2/137 in Trishal and 10/59 in Godagari. Most of the VL deaths (9/12, 75\%) occurred at home and the rest in tertiary hospitals. None of these deaths had been reported in the national $\mathrm{VL}$ surveillance system. The VL case fatality rate in the Tribal ethnic (22.2\%) population was about 17 times higher than that in the Bangali ethnic (1.3\%) population $(p<0.0001)$. Tribal ethnicity had an 18 times (OR=18.1, 95\% $\mathrm{Cl} 3.6$ to 90.6) higher risk for VL deaths compared with Bangali ethnicity $(p<0.0001)$. Conclusion: VL deaths were found to be high in the study areas and were under-reported. The Tribal ethnic population was at the highest risk for VL deaths. The national VL Elimination Programme should give special attention to the tribal community in the endemic areas, especially for those in Rajshahi, and should strengthen VL surveillance by including tertiary hospitals in the national surveillance system.

\section{INTRODUCTION}

Leishmaniasis is one of the most important vector-borne diseases with an estimated 1.98 million disability adjusted life years and $20000-40000$ deaths per annum. ${ }^{1}{ }^{2}$ Recent empirical estimates found the annual

\section{Strength and limitations of this study}

- This is the first study in the South East Asia Region, in which visceral leishmaniasis (VL)-related mortality was investigated in Bangladesh using the verbal autopsy procedure.

- The study is limited to only two unions of VL endemic districts.

- The recall bias in the study cannot be excluded, but we tried to minimise this by probing with different events that occurred during the past 2 years from the date of the interview.

incidence of visceral leishmaniasis (VL) and cutaneous leishmaniasis (CL) to be 0.2-0.4 and $0.7-1.2$ million cases, respectively. ${ }^{1}$ Ninety per cent of the global burden of VL occurred in India, Bangladesh, Sudan, South Sudan, Brazil and Ethiopia. ${ }^{1}$ In the Indian subcontinent, the estimated population at risk for VL, annual VL incidence and VL death are 200 million , 25000 to 40000 cases and 200 to 300 deaths respectively. ${ }^{3}$ For many years, there have been a substantial number of VL cases that have never been reported due to the lack of proper surveillance systems which contributes to the neglect of this disease.

In Bangladesh, VL re-emerged in the early 1980 s, and since then more than 90000 cases have been documented. ${ }^{4}{ }^{5}$ Since 1996 , the reported VL incidence in Bangladesh has ranged from 7000 to 9000 cases per year, but this is likely to be underestimated. ${ }^{6}$ After adjusting the substantial under-reporting factor, the recent estimated VL incidence in Bangladesh ranges from 12400 to 24900 cases per year. ${ }^{1}$ The disease is prevalent in 45 districts of Bangladesh; however, most of the cases are reported from the Mymensingh district. $^{4} 5$ The female Phlebotomas argentipes sandfly is the only vector; humans are the only reservoir and Leishmania donovani is the only species responsible for VL in the Indian subcontinent, including Bangladesh. ${ }^{3-5}$ The 
disease is fatal if not treated. Even with treatment, the mortality rate is high $(10 \%) .^{7}$ In 2005 , a national VL Elimination Programme has been launched jointly by the Health Ministries from Bangladesh, India and Nepal to eliminate VL by 2015. ${ }^{8}$ In Bangladesh, the goal of the elimination programme is to reduce VL cases below 1 per 10000 people in the VL endemic subdistricts (known as Upazila). ${ }^{8}$ The strategies for VL elimination include active detection of VL and post-kala-azar dermal leishmaniasis (PKDL) cases, adequate treatment of VL and PKDL cases, interruption of disease transmission through integrated vector management, and social mobilisation. ${ }^{89}$ Since 2006, several operational research activities have been conducted by government and nongovernment organisations to support the national elimination programme in Bangladesh. These programmes revealed that the passive case detection (existing surveillance system) highly underestimated VL cases in Bangladesh. ${ }^{10-12}$ In 2008, a study conducted in the Rajshahi district showed that the incidence of VL was 27 times higher than the elimination target. It also found that the knowledge of the community people about VL and its vector was poor and their health seeking behaviour was also unsatisfactory. ${ }^{12}$

Similar to VL case reporting, it can be assumed that the mortality rate of VL is also highly underestimated in Bangladesh. Until now, there is no well-designed study to measure VL mortality in highly VL endemic areas of Bangladesh. According to the Directorate General of Health Services, the reported annual number of $\mathrm{VL}$ deaths varied from 6 to 36 during 1999-2009. ${ }^{13}$ This appears to be highly underestimated because a community-based study in a small endemic area reported a high VL mortality rate (about $10.0 \%$ ) in $2003 .{ }^{14}$ The possible reason for the high underestimation of VL deaths might be a shortfall in the passive reporting system which does not include tertiary hospitals under VL case surveillance. VL patients who are poor and living in remote communities far from healthcare facilities often die at home without seeking treatment or prefer traditional healers for their healthcare and do not report to the public health facilities. Underestimation of deaths contributes to VL remaining a major neglected tropical disease. Thus, there is a need to investigate the magnitude of VL deaths and its risk factors through a welldesigned study and by using adequate tools for investigation of death. Culturally, autopsy is not well accepted in Bangladesh. Verbal autopsy (VA) could be the alternative since it is the best available approach for assessing causes of death in the communities where most deaths occur at home. ${ }^{7}$ Until now, no study has been conducted to investigate VL deaths in the Indian subcontinent including Bangladesh after the start of the VL Elimination Programme. We have therefore undertaken this study to fill this knowledge gap in Bangladesh. The objective of this study is to estimate the VL mortality and risk factors in two geographically and culturally different and highly VL endemic areas of Bangladesh.

\section{METHODS}

\section{Study sites and population}

The study was carried out in the two different VL endemic areas of Bangladesh, the Godagari subdistrict in the district of Rajshahi and the Trishal subdistrict in the Mymensingh district. Both Trishal and Godagari are highly endemic for VL. The study activities were performed from July to December 2011. Mymensingh district reports more than $60 \%$ of the total VL cases in the country. Trishal is one of the five most VL endemic subdistricts in Mymensingh and is located at $24.5792742^{\circ} \mathrm{N}$ $90.3950388^{\circ} \mathrm{E}$. Trishal consists of 12 unions and 160 villages and all the unions are endemic for VL. Godagari is one of the highest VL endemic subdistricts in Rajshahi, which is located at $24.4667^{\circ} \mathrm{N} 88.3306^{\circ} \mathrm{E}$ with 9 unions and 396 villages and has a significant tribal population. Godagari was included in the study to investigate VL deaths among the tribal population and to compare them with those of the Bangali ethnic population. Based on our past experiences, we assumed that the tribal population was at higher risk for VL deaths.

\section{Sample size estimation}

It was reported that the VL case fatality rate (CFR) was about 10\% in 2003 in VL endemic areas in Mymensingh district. ${ }^{14}$ We assumed a significant reduction of CFR along with the reduction of VL incidence as a benefit of the VL Elimination Programme in Bangladesh. We therefore calculated the sample size assuming an average of $6.5 \%$ CFR with $\pm 3.0 \%$ precision and $95 \%$ CI. A total of $191 \mathrm{VL}$ cases were needed to obtain a $6.5 \%$ CFR in the study areas. To obtain a minimum of 191 past VL cases in the past 2 years, the survey required a total of 47750 people (considering an annual VL incidence of 20/10 000). The study areas included a population of 51094 (24934 from Trishal and 26160 from Godagari).

\section{Study design and sampling}

The study design was retrospective cross-sectional. As mentioned above, we selected Trishal and Godagari subdistricts and one endemic union from each subdistrict was taken randomly (figure 1). The trained field research assistants (FRAs) visited each household, made household rosters and collected sociodemographic information from the head of the household. During their visit, FRAs also identified households with past cases of VL, any death and suspected VL deaths within the past 2 years. To minimise recall bias, the FRAs used probing with different events (mainly religious festivals) that occurred during the past 2 years from the date of the interview. We defined a suspected VL death as a death with a history of VL treatment or a death with an illness associated with two or more weeks of fever, plus at least one of the following: weight loss, enlarged abdomen, abdominal pain and/or skin darkening. Then the VA method was applied to confirm the suspected VL death (please see below). A household with a VL death 
Figure 1 Study profile $(\mathrm{HH}$, household; VA, verbal autopsy; $\mathrm{VL}$, visceral leishmaniasis).

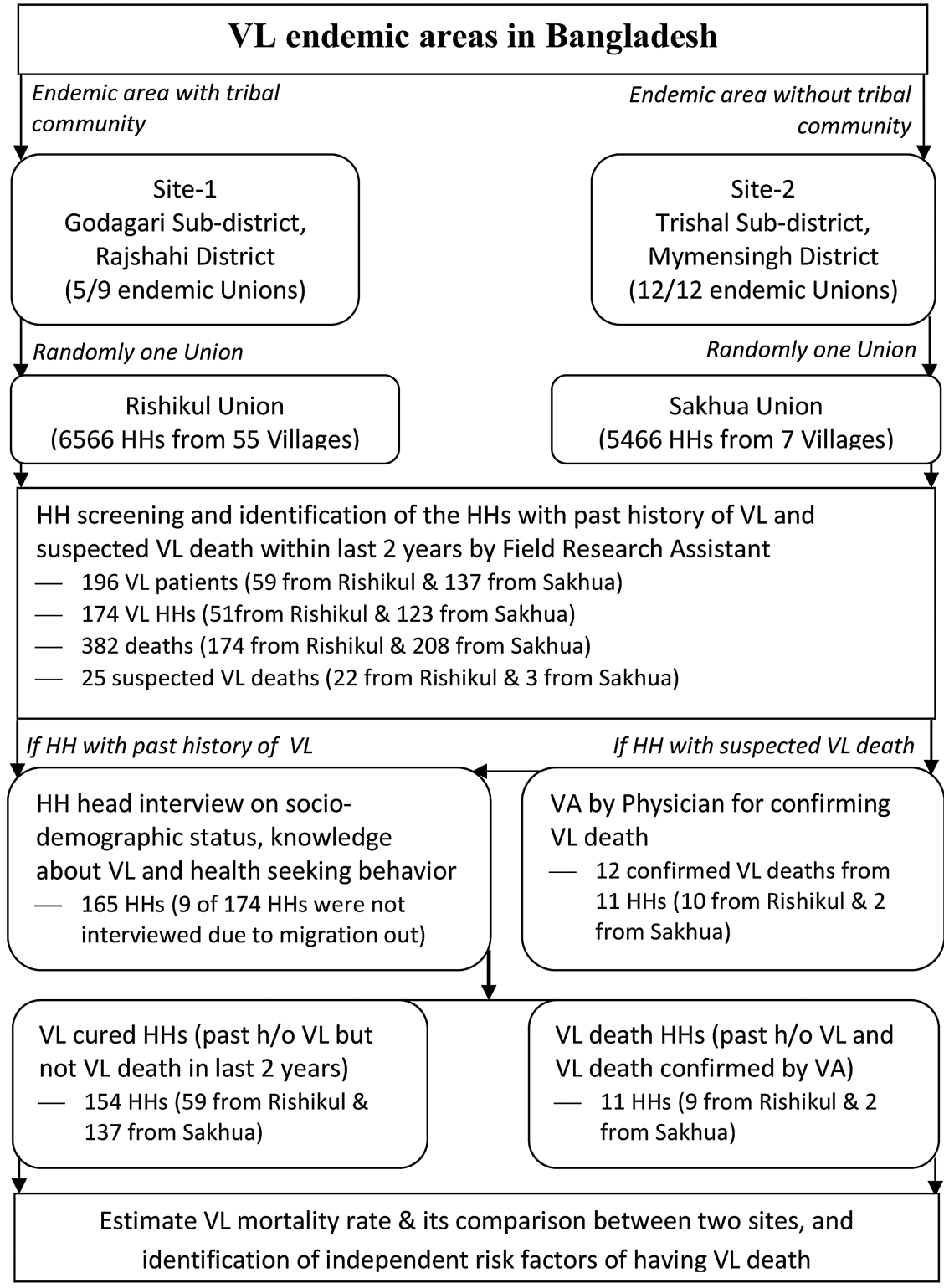

confirmed by VA was defined as a VL death household. The household with a history of VL but no deaths in the past 2 years was defined as a VL cured household (figure 1). Household heads from both VL death and VL cured households were interviewed by the FRAs with a structured questionnaire for collection of information about the households' socioeconomic status, knowledge about VL and its vector, and for information about the treatment seeking behaviour used. At the same time, the coordinates (longitude and latitude) of all the households in the study area were recorded using eTrex Venture Garmin single handheld GPS receivers.

\section{VA at suspected VL death household}

We developed an interview questionnaire for VA followed by an ICD 10 VA guideline and the questionnaire was reviewed by a VL expert. We also translated the questionnaire into the local language, and it has been further reviewed, revised and approved by the icddr,b Ethical Review Committee. Briefly, the tool assessed the identity of the deceased and established the sequences of the events leading to death including signs and symptoms of the illness before death. It is recommended that VA should be performed within 3 months to 2 years to minimise recall bias. ${ }^{15}$ After identifying the household with a suspected VL death, a VL expert physician visited the household immediately with an FRA and conducted the VA. Respondents for the interview were household heads/close relatives. Studies with VA showed that close relatives rarely refuse to give information and in some situations the response rates were $100 \% .^{16-18}$ A second VL expert physician reviewed each VA questionnaire independently. In case of disagreement between the first and the second physician, the VA questionnaires were reviewed by a third expert physician and his verdict was final.

\section{Statistical analysis}

All data were entered and stored in a well-checked data entry program developed by EPI Info software (Centers 
for Disease Control and Prevention, Atlanta, Georgia, USA). Data were cleaned and checked for duplicates. We explored the descriptive statistics to consider the nature of data. We calculated the CFR and compared the rates between different study sites (Godagari vs Trishal) and ethnic groups (Tribal vs Bangali) with the Z-test. We dichotomised socioeconomic, knowledge about VL, and health seeking behaviour variables for bivariate analysis. Variables which showed significant $(p \leq 0.05)$ association with VL death in the bivariate analysis (Pearson's $\chi 2$ and Fisher exact tests, where applicable) were included in the logistic regression model. The final model was obtained by a backward selection strategy recommended by Kleinbaum et al. ${ }^{19}$ The statistical software SPSS V.13.0 for windows (SPSS, Chicago, Illinois, USA) was used to carry out all the analyses. We constructed the study area map with spatial distribution of households in the study areas by using ArcView GIS V.3.2 (ArcGIS, ESRI, Redlands, California, USA).

\section{RESULTS}

Sociodemographic characteristics of the study population

A total of 51094 people (12032 households) were studied where 26160 (6566 households) came from the Rishikul Union in the subdistrict of Godagari in the district of Rajshahi and the rest of the people from the Sakhua Union in the subdistrict of Trishal in the Mymensingh district. The average age of the study population was 25.6 years (SD 18.4) and $49.7 \%$ were females (table 1). About $16 \%(n=4243)$ of the population was tribal in Godagari, whereas all the people are non-tribal (Bangali ethnicity) in the Trishal area (table 1).

\section{VL-associated mortality based on VA}

During the period August 2009-December 2011, VL affected $0.4 \%(196 / 51094)$ of the people in the study areas. The proportion of the VL affected population was higher in Trishal $(0.5 \%, 137 / 24934)$ compared with Godagari $(0.2 \%, 59 / 26$ 160). Trained FRAs suspected a total of 25 VL deaths and VL expert physicians confirmed VL deaths in $12 / 25$ by VA. The VL deaths in two areas averaged $6.12 \%(12 / 196)$ and accounted for $3.14 \%$ (12/ 382) of the total deaths in the study areas. The VL CFR differed significantly from Godagari than Trishal and was $17 \%(10 / 59)$ and $1.5 \%(2 / 137)$, respectively $(\mathrm{p}<0.0001)$ (table 2). The VL CFR in the Tribal population $(22.2 \%)$ was about 17 times higher than the non-tribal/Bangali ethnic $(1.3 \%)$ population $(\mathrm{p}<0.0001)$.

Among the 12 confirmed VL deaths, $50 \%$ (6/12) were children aged below 17 years and $75 \%(9 / 12)$ were male. Most of the deaths occurred in tribal ethnic populations, which accounted for $83.3 \%(10 / 12)$ of total VL deaths. About 33.3\% (4/12) of all confirmed deaths did not receive treatment during their illness that led to death. Tuberculosis as an associated illness was found in $8.3 \%(1 / 12)$ of the deceased. The majority of the deaths occurred at home and the rest were in the tertiary hospital (table 3). While checking the existing VL surveillance data, none of these 12 VL deaths were found. The spatial distribution of households with VL and VL deaths during August 2009-December 2011 is shown in figure 2.

\section{Factors associated with VL death}

To identify factors associated with VL death households, we compared household-related information between 11 VL death households and 154 VL cured households. Bivariate association showed that households with a VL death differ significantly between Tribal-ethnic and Bangali-ethnic groups $(\mathrm{p}<0.0001)$. The VL death households were socioeconomically poorer than VL cured households as daily labour household head, low monthly household income, and precarious housing structures were significantly more in VL death households. (table 4). The level of knowledge about VL was, however,

Table 1 Sociodemographic characteristics and history of $\mathrm{VL}$ and death in the study population

\begin{tabular}{llll} 
& Trishal, Mymensingh & Godagari, Rajshahi & Total \\
\hline Total population & 24934 & 26160 & 51094 \\
Total household & 5466 & 6566 & 12032 \\
Mean age (SD) & $24.53(18.91)$ & $26.70(17.92)$ & $25.65(18.44)$ \\
Age ratio (years) & & & \\
$\quad<17$ & $10868(43.6)$ & $9309(35.6)$ & $20177(39.5)$ \\
$\quad 17-45$ & $10091(40.5)$ & $12895(49.3)$ & $22986(45.0)$ \\
$\quad>45$ & $3975(15.9)$ & $3956(15.1)$ & $7931(15.5)$ \\
Male population & $12958(52.0)$ & $13267(50.7)$ & $26225(51.3)$ \\
Ethnicity & & & \\
$\quad$ Bangali & $24934(100.0)$ & $21917(83.8)$ & $46851(91.7)$ \\
$\quad$ Tribal & $00(0.0)$ & $4243(16.2)$ & $4243(8.3)$ \\
Past h/o VL in the past 2 years & $137(0.5)$ & $59(0.2)$ & $196(0.4)$ \\
Total deaths reported by respondent in the past 2 years & 208 & 174 & 382 \\
Total suspected VL deaths in the past 2 years & 3 & 22 & 25 \\
Total VL deaths in the past 2 years confirmed by VA & 2 & 10 & 12 \\
\hline VA, verbal autopsy; VL, visceral leishmaniasis. & & &
\end{tabular}




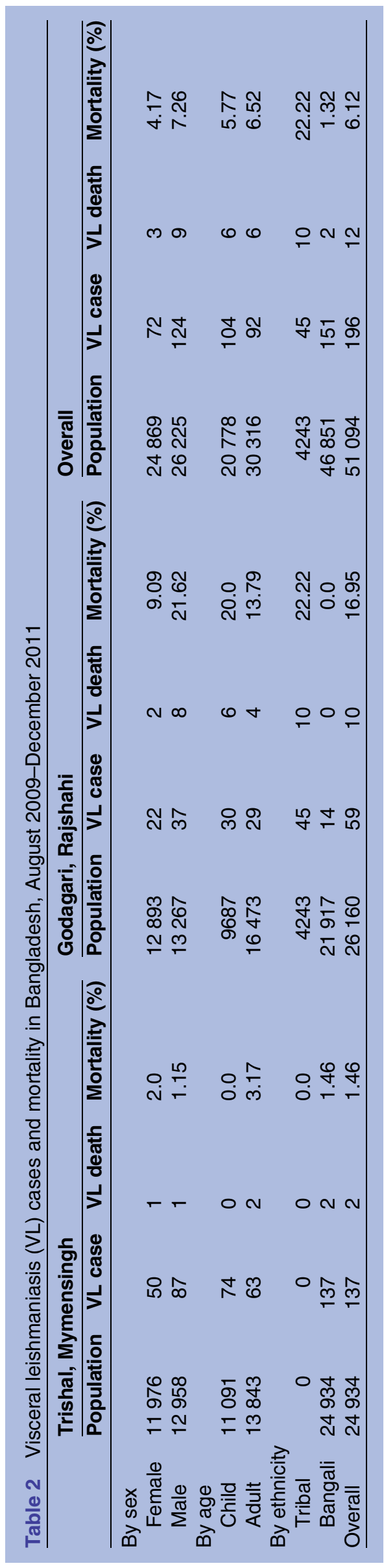

almost the same between the two groups (table 4). Although the general health seeking behaviour of VL death and VL cured households was the same $(p=0.431)$, their VL health seeking behaviour differed significantly ( $p=0.013$; table 4 ). About $92.2 \%$ (142/154) of VL cured households visited qualified doctors when members of the family had VL, whereas only $63.6 \%(7 / 11)$ of VL death households visited qualified doctors for the same.

The logistic regression model showed that ethnicity was the only independent risk factor for VL death. The adjusted model showed that households of Tribal ethnicity were at 18 (OR=18.1, 95\% CI 3.6 to 90.6) times higher risk of having a VL death than households of Bangali ethnicity $(\mathrm{p}<0.0001)$ (table 5$)$.

\section{DISCUSSION}

Our study is the first to estimate the actual mortality of VL in Bangladesh through VA, and the major findings of the study are as follows : VL mortality in the endemic community remains high, the tribal population is at higher risk for VL deaths and there is under-reporting of VL deaths by the existing VL surveillance system. The findings of our study are very important for the National VL Elimination Programme, because it may help the programme to make better plan to further reduce VL related mortality.

\section{Comparison with other studies}

It is alarming that the VL CFR is very high in the Tribal community in Rajshahi; it was found to be about $22 \%$. The probable cause of the high VL CFR in that community could be their poor health seeking behaviours as they rarely visit government hospitals due to cultural beliefs and prefer traditional healers. ${ }^{20}$ As a result, VL patients in that community remain untreated and die at home. We found that about $33 \%$ confirmed that VL deaths were not treated before dying and that all those untreated belonged to the Tribal community in Rajshahi. A previous study ${ }^{12}$ conducted on the same community also identified a lack of access to proper healthcare, including high delay in VL diagnosis and treatment. Although Mymensingh is highly endemic for VL, the CFR of VL patients living in Mymensingh (all are of Bangali ethnicity) was not as high as that of those in Rajshahi district. Additionally, we found low VL mortality in Mymensingh as compared with the reported VL mortality in 2003. ${ }^{14}$ The lower VL mortality in Mymensingh can be explained by the more focused attention paid to this highly endemic area by the national VL Elimination Programme of the country.

The hospital-based VL CFR is substantially underestimated in the Indian subcontinent, including Bangladesh. ${ }^{1}$ In Bangladesh, the existing hospital based surveillance system is mainly based on the passive reporting system. There is no active follow-up of VL patients who had been treated in the hospital. As a result, the patients who died in the community/home are missed 
Table 3 Characteristics of VL deceased confirmed by verbal autopsy

\begin{tabular}{|c|c|c|c|}
\hline & \multicolumn{3}{|c|}{ VL deceased; n (\%) } \\
\hline & $\begin{array}{l}\text { Male } \\
\mathrm{N}=9\end{array}$ & $\begin{array}{l}\text { Female } \\
\mathrm{N}=3\end{array}$ & $\begin{array}{l}\text { Overall } \\
\mathrm{N}=12\end{array}$ \\
\hline \multicolumn{4}{|l|}{ Age group (years) } \\
\hline$<17$ & $4(44.4)$ & $2(66.7)$ & $6(50.0)$ \\
\hline $17-45$ & $5(55.6)$ & 1 (33.3) & $6(50.0)$ \\
\hline$>45$ & $0(0.0)$ & $0(0.0)$ & $0(0.0)$ \\
\hline \multicolumn{4}{|l|}{ Ethnicity } \\
\hline Tribal & $8(88.9)$ & $2(66.7)$ & $10(83.3)$ \\
\hline Bangali & $1(11.1)$ & 1 (33.3) & $2(16.7)$ \\
\hline Received treatment before death & $5(55.6)$ & $3(100.0)$ & $8(66.7)$ \\
\hline Having TB co-infection & $0(0.0)$ & $1(33.3)$ & $1(8.3)$ \\
\hline \multicolumn{4}{|l|}{ Place of death } \\
\hline Home & $7(77.8)$ & $2(66.7)$ & $9(75.0)$ \\
\hline Hospital (tertiary) & $2(22.2)$ & 1 (33.3) & $3(25.0)$ \\
\hline
\end{tabular}

by the existing surveillance systems. Until recently, the tertiary hospitals did not report VL cases to the national programme. Even very recently, only two tertiary hospitals started reporting VL cases to the national surveillance system. Our study results complied with these facts. Forty-two per cent $(5 / 12)$ of VL deaths occurred at home, although they had been treated in the hospitals. Twenty-five per cent $(3 / 12)$ died in the tertiary hospitals and the rest $33 \%(4 / 12)$ died at home without treatment. It is surprising that none of these $12 \mathrm{VL}$ deaths were reported by the VL national programme even when the deaths occurred in the tertiary hospital.

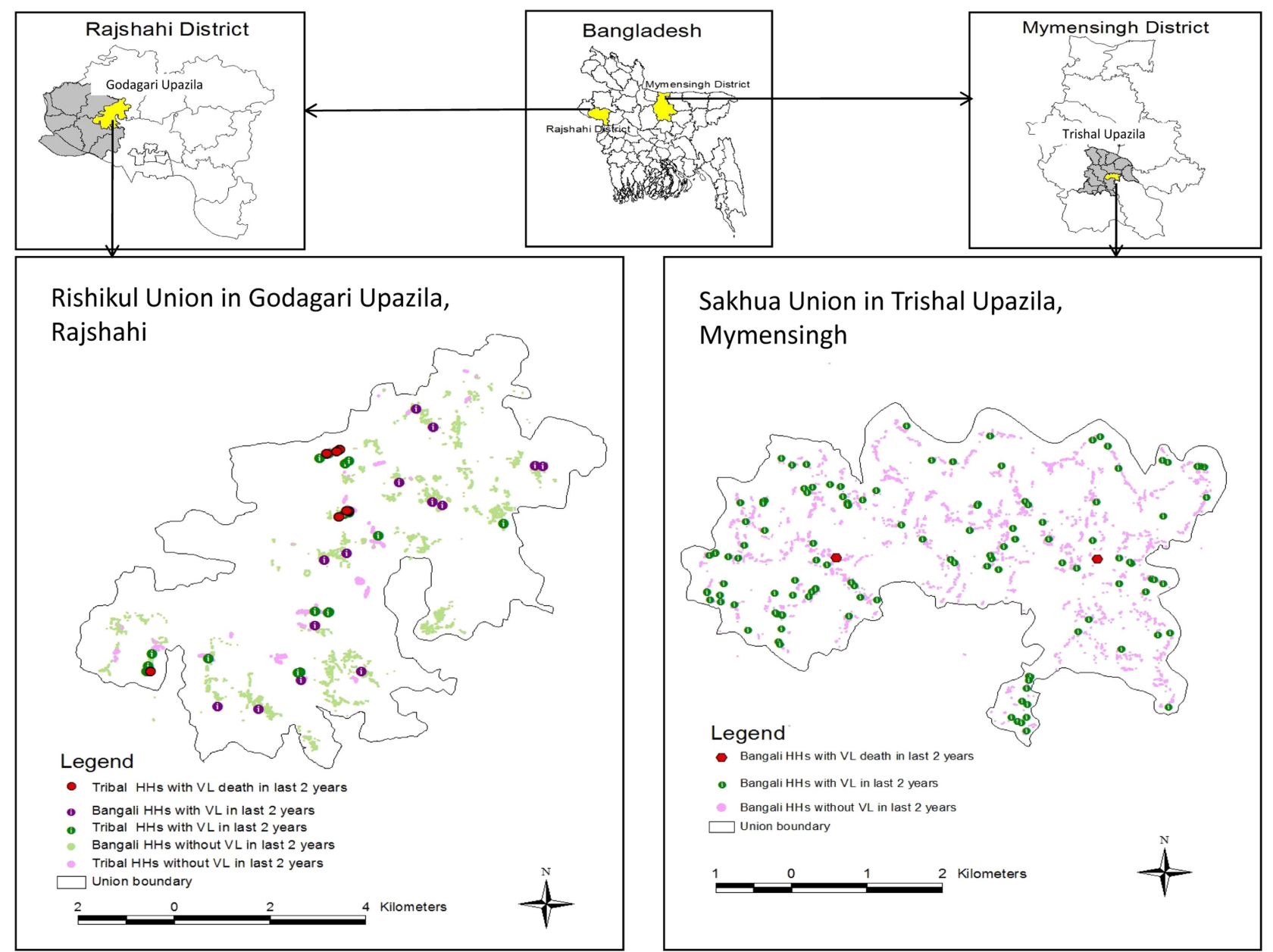

Figure 2 Study area map including spatial distribution of households, households with visceral leishmaniasis (VL) and VL deaths during August 2009-December 2011 (HH, household). 
Table 4 VL death and VL cured households and the bivariate analysis for socioeconomic, VL knowledge and health seeking behaviour-related information

\begin{tabular}{|c|c|c|c|}
\hline & $\begin{array}{l}\text { VL death HH } \\
\mathrm{N}=11 \\
\mathrm{n}(\%)\end{array}$ & $\begin{array}{l}\text { VL cured HH } \\
\mathrm{N}=154 \\
\mathrm{n}(\%)\end{array}$ & p Value \\
\hline \multicolumn{4}{|l|}{ Study site } \\
\hline Mymensingh & $2(18.2)$ & $115(74.7)$ & \multirow[t]{2}{*}{$<0.0001$} \\
\hline Rajshahi & $9(81.8)$ & 39 (25.3) & \\
\hline \multicolumn{4}{|l|}{ Socioeconomic status } \\
\hline Illiterate $\mathrm{HH}$ head & $6(54.5)$ & $74(48.1)$ & 0.677 \\
\hline Daily labour $\mathrm{HH}$ head & $10(90.9)$ & $64(41.6)$ & 0.003 \\
\hline Income about <US\$ 100 & $11(100.0)$ & $101(65.6)$ & 0.017 \\
\hline Precarious house & $10(90.9)$ & $83(53.9)$ & 0.024 \\
\hline Living room with <2 & $7(63.6)$ & $67(43.5)$ & 0.223 \\
\hline Family size with $<5$ members & $2(18.2)$ & $57(37.0)$ & 0.331 \\
\hline Having bed-nets & $11(100.0)$ & $152(98.7)$ & 1.00 \\
\hline Having domestic animals & $10(90.9)$ & $130(84.4)$ & 1.00 \\
\hline \multicolumn{4}{|l|}{ Knowledge about VL } \\
\hline Symptoms & $11(100.0)$ & $136(88.3)$ & 0.611 \\
\hline Transmitted by mosquito/sandfly & $6(54.5)$ & $71(46.1)$ & 0.588 \\
\hline The disease is curable & $11(100.0)$ & $147(95.5)$ & 1.000 \\
\hline \multicolumn{4}{|l|}{ Health seeking behaviours } \\
\hline Visit qualified doctor when get any sick & $1(9.1)$ & $7(4.5)$ & 0.431 \\
\hline Visit qualified doctor when get VL & 7 (63.6) & $142(92.2)$ & 0.013 \\
\hline \multicolumn{4}{|l|}{ Ethnicity } \\
\hline Bangali & $2(18.2)$ & $127(82.5)$ & \multirow[t]{2}{*}{$<0.0001$} \\
\hline Tribal & $9(81.8)$ & 27 (17.5) & \\
\hline
\end{tabular}

$\mathrm{HH}$, household; VL, visceral leishmaniasis.

Thus, VL deaths are highly under-reported. Therefore, there is an urgent need for improvement of the existing surveillance system, implementation of active surveillance of VL patients under treatment and inclusion of the tertiary hospitals (especially those in the VL endemic areas) under a routine VL case reporting mechanism.

Another important finding of the study is that about $8 \%$ of the VL deceased had tuberculosis, which indicates the existence of VL-tuberculosis coinfection in VL endemic areas of Bangladesh. The evidence of VL associated with tuberculosis has been reported in several VL endemic countries, including India. ${ }^{21}$ However, this type of data has not been previously reported from Bangladesh.

Although there are previous reports ${ }^{22-24}$ on clinical risk factors for VL death, so far our study is the first where household-level risk factors were explored. Households with VL deaths were found to be socioeconomically poorer than those without VL deaths. Moreover, poorer VL health seeking behaviour was observed in households with VL deaths. Tribal ethnicity was the only independent risk factor for VL death in the adjusted regression model. This is because the tribal ethnic populations are comparatively poorer, less educated and less aware about healthcare compared with the Bangali ethnic population. The VL Elimination Programme should therefore take the necessary steps to improve the VL health seeking behaviour of the tribal population, especially those in the Rajshahi VL endemic areas, to minimise their risk from VL death.

\section{CONCLUSION}

This study highlighted VL mortality in two VL endemic areas of Bangladesh, underlined the under-reporting of VL deaths and found tribal ethnic populations to be at

Table 5 Independent risk factor on visceral leishmaniasis death (OR adjust using stepwise logistic regression)

\begin{tabular}{|c|c|c|c|c|c|c|c|}
\hline Variable & VL death HH & VL cured HH & OR & $(95 \% \mathrm{Cl})$ & Adjusted OR* & $(95 \% \mathrm{Cl})$ & p Value \\
\hline \multicolumn{8}{|l|}{ Ethnicity } \\
\hline Tribal & 9 & 27 & 21.2 & (4.3 to 103.5$)$ & 18.1 & (3.6 to 90.6 ) & $<0.0001$ \\
\hline Bangali & 2 & 127 & 1.00 & & 1.00 & & \\
\hline \multicolumn{8}{|c|}{ VL health seeking behaviour } \\
\hline Unqualified doctor & 4 & 12 & 6.8 & (1.7 to 26.4$)$ & 4.3 & (1.00 to 20.5$)$ & 0.063 \\
\hline Qualified doctor & 7 & 142 & 1.00 & & 1.00 & & \\
\hline
\end{tabular}

${ }^{*}$ Adjusted by study site, household head occupation, income, housing structure.

VL, visceral leishmaniasis; $\mathrm{HH}$, household. 
higher risk for VL death. A substantial number of VL patients never visit hospital for proper healthcare and die at home. The national VL Elimination Programme should give special attention to the tribal community in the VL endemic areas of Bangladesh and the existing surveillance systems must be improved by integrating active case detection as well as the active follow-up of the treated patients.

\section{Author affiliations}

${ }^{1}$ Centre for Population, Urbanization and Climate Change, icddr,b, Dhaka, Bangladesh

${ }^{2}$ Department of Medical Entomology, National Institution of Preventive and Social Medicine, Dhaka, Bangladesh

${ }^{3}$ Regional Office for South-East Asia, World Health Organization, New Delhi, India

${ }^{4}$ The National Academy of Sciences India, Allahabad, India

${ }^{5}$ Centre for Nutrition and Food Security, icddr,b, Dhaka, Bangladesh

Acknowledgements icddr,b acknowledges with gratitude the commitment of the WHO to its research efforts. The authors wish to thank Dr Greg Matlashewski for his valuable comments and support. They also thank all participants who consented to participate in the study.

Contributors $\mathrm{MMH}$ and DM conceived and designed the study. MMH, RC, $A P D, S K B$ and DM wrote the paper. MMH performed the statistical analysis. DG participated in its design and coordination and helped to draft the manuscript. All authors read and approved the final manuscript. MMH is the study guarantor.

Funding This study was funded by the WHO. Award no. 57532 .

Competing interests None.

Patient consent Obtained.

Ethics approval The study was approved by the institutional Ethical Review Committee of icddr,b, Dhaka, Bangladesh (Research Protocol \# PR-11027). All households in the study areas were enrolled in the study after obtaining written consent from the head of the household. Informed consent was obtained from the respondent (head of the household/close relatives) before conducting verbal autopsy.

Provenance and peer review Not commissioned; externally peer reviewed.

Data sharing statement No additional data are available.

Open Access This is an Open Access article distributed in accordance with the Creative Commons Attribution Non Commercial (CC BY-NC 4.0) license, which permits others to distribute, remix, adapt, build upon this work noncommercially, and license their derivative works on different terms, provided the original work is properly cited and the use is non-commercial. See: http:// creativecommons.org/licenses/by-nc/4.0/

\section{REFERENCES}

1. Alvar J, Velez ID, Bern C, et al. Leishmaniasis worldwide and global estimates of its incidence. PLoS ONE 2012;7:e35671.

2. WHO. The world health report 2000 health systems: improving performance. Geneva: World Health Organization, 2000.
3. Joshi A, Narain JP, Prasittisuk C, et al. Can visceral leishmaniasis be eliminated from Asia? J Vector Borne Dis 2008;45:105-11.

4. Bern C, Chowdhury R. The epidemiology of visceral leishmaniasis in Bangladesh: prospects for improved control. Indian J Med Res 2006;123:275-88.

5. Rahman R, Bangali M, Kabir $\mathrm{H}$, et al. Kala-azar situation in Bangladesh. In: Hossain M, ed. National guideline and training module for kala-azar elimination in Bangladesh. 1st edn. Dhaka: CDC, DGHS, Ministry of Health and Family Welfare, Government of the People's Republic of Bangladesh, 2008;11-2.

6. Ahluwalia IB, Bern C, Wagatsuma Y, et al. Visceral leishmaniasis: consequences to women in a Bangladeshi community. J Womens Health (Larchmt) 2004:13:360-4.

7. Berman JD. Human leishmaniasis: clinical, diagnostic, and chemotherapeutic developments in the last 10 years. Clin Infect Dis 1997;24:684-703.

8. WHO. Regional Technical Advisory Group on Kala-azar Elimination. Report of the first meeting, Manesar, Haryana, 20-23 December 2004. New Delhi: Regional Office for South-East Asia, 2005.

9. WHO. Regional Strategic Framework for Elimination of Kala-azar from the South-East Asia Region (2005-2015). New Delhi: Regional Office for South-East Asia, 2004.

10. Hirve S, Singh SP, Kumar N, et al. Effectiveness and feasibility of active and passive case detection in the visceral leishmaniasis elimination initiative in India, Bangladesh, and Nepal. Am J Trop Med Hyg 2010;83:507-11.

11. Mondal D, Nasrin KN, Huda MM, et al. Enhanced case detection and improved diagnosis of PKDL in a Kala-azar-endemic area of Bangladesh. PLoS Negl Trop Dis 2010;4:pii: e832.

12. Mondal D, Singh SP, Kumar N, et al. Visceral leishmaniasis elimination programme in India, Bangladesh, and Nepal: reshaping the case finding/case management strategy. PLoS Negl Trop Dis 2009;3:e355.

13. MOHFW. Tropical diseases in Bangladesh: situation analysis and gap analysis. Ministry of Health and Family Welfare, Government of Bangladesh, 2011.

14. Ahluwalia IB, Bern C, Costa C, et al. Visceral leishmaniasis: consequences of a neglected disease in a Bangladeshi community. Am J Trop Med Hyg 2003;69:624-8.

15. Fottrell E, Byass P. Verbal autopsy: methods in transition. Epidemiol Rev 2010;32:38-55.

16. Chandramohan $\mathrm{D}$, Soleman $\mathrm{N}$, Shibuya $\mathrm{K}$, et al. Ethical issues in the application of verbal autopsies in mortality surveillance systems. Trop Med Int Health 2005;10:1087-9.

17. Gajalakshmi V, Peto R. Verbal autopsy of 80,000 adult deaths in Tamilnadu, South India. BMC Public Health 2004;4:47.

18. Kahn K, Tollman SM, Garenne M, et al. Validation and application of verbal autopsies in a rural area of South Africa. Trop Med Int Health 2000:5:824-31.

19. Kleinbaum DG, Kupper LL, Muller KE, et al. Applied regression analysis and other multivariable methods. 3rd edn. Pacific Grove, CA: Duxbury Press, 1998.

20. Rahman SA, Kielmann T, McPake B, et al. Healthcare-seeking behaviour among the tribal people of Bangladesh: can the current health system really meet their needs? J Health Popul Nutr 2012;30:353-65.

21. Li XX, Zhou XN. Co-infection of tuberculosis and parasitic diseases in humans: a systematic review. Parasit Vectors 2013;6:79.

22. de Araujo VE, Morais MH, Reis IA, et al. Early clinical manifestations associated with death from visceral leishmaniasis. PLoS Negl Trop Dis 2012;6:e1511.

23. Mueller $Y$, Mbulamberi DB, Odermatt $P$, et al. Risk factors for in-hospital mortality of visceral leishmaniasis patients in eastern Uganda. Trop Med Int Health 2009;14:910-17.

24. Sampaio MJ, Cavalcanti NV, Alves JG, et al. Risk factors for death in children with visceral leishmaniasis. PLoS Negl Trop Dis 2010;4: e877. 